\title{
Torta de girassol em substituição ao farelo de soja nos suplementos de novilhas: desempenho e características de carcaça
}

\author{
Sunflower crushed in substitution of soybean meal for heifers at pasture: performance \\ and carcass characteristics
}

\begin{abstract}
GOES, Rafael Henrique de Tonissi e Buschinelli de ${ }^{1^{*}}$; CERILO, Sara Letícia Nocchi ${ }^{2}$; LIMA, Hellen Leles ${ }^{2 ;}$ FERNANDES, Alexandre Rodrigo Mendes ${ }^{1}$; OLIVEIRA, Euclides Reuter de ${ }^{1}$; SOUZA, Kennyson Alves de ${ }^{2}$; PATUSSI, Rosiélen Augusto ${ }^{2}$; BRABES, Kelly Cristina da Silva ${ }^{3}$; GRESSLER, Maria Gizelma de Menezes ${ }^{1}$
\end{abstract}

\footnotetext{
${ }^{1}$ Universidade Federal da Grande Dourados, Faculdade de Ciências Agrárias, Dourados, Mato Grosso do Sul, Brasil.

${ }^{2}$ Universidade Federal da Grande Dourados, Programa de Pós-Graduação em Zootecnia, Dourados, Mato Grosso do Sul, Brasil.

${ }^{3}$ Universidade Federal da Grande Dourados, Faculdade de Engenharia, Dourados, Mato Grosso do Sul, Brasil.

*Endereço para correspondência: rafaelgoes@ufgd.edu.br
}

\section{RESUMO}

Para se avaliar o desempenho de novilhas Nelore suplementadas com torta de girassol em substituição ao farelo de soja em 0; 20; 40 e 60\% foram utilizados 24 animais, durante a época seca, em delineamento inteiramente casualizado. Os animais foram pesados e monitorados quanto à condição corporal a cada 21 dias. A inclusão de torta de girassol melhorou o ganho de peso diário em $45,8 \%$. A eficiência do uso de concentrados foi de 12,$26 ; 13,42$ e $9,87 \mathrm{~kg} / \mathrm{kg}$ para os níveis de substituição de 20,40 e $60 \%$ e o suplemento sem torta de girassol teve eficiência de $7,31 \mathrm{~kg} / \mathrm{kg}$. A condição corporal dos animais melhorou com o fornecimento dos suplementos, sendo a condição corporal final 3,6; 4,0; 4,0 e 3,7 pontos; para os níveis de substituição de 00, 20, 40 e $60 \%$. Para as características de carcaça não ocorreram diferenças significativas entre os níveis de substituição estudados para peso de abate, peso de carcaça quente, peso de carcaça fria, perdas por resfriamento, rendimento de carcaça, comprimento de carcaça, traseiro, dianteiro, carne aproveitável total, cortes comerciais brasileiros, AOL $/ 100 \mathrm{~kg}$, espessura de gordura, fígado. Verificou-se efeito para substituição da torta de girassol somente para acúmulo de gordura perirrenal-pélvica, onde o nível de $60 \%$ apresentou o maior valor $(3,67 \mathrm{~kg})$. A substituição parcial do farelo de soja por torta de girassol melhorou o desempenho de novilhas terminadas a pasto, sem alterar as características de carcaça dos animais.

Palavras-chave: área de olho de lombo, carne aproveitável total, coproduto, ganho de peso, suplementação

\section{SUMMARY}

To evaluate the performance of Nellore heifers supplemented with sunflower cake in partial substitution of soybean meal at $0 ; 20 ; 40$ and $60 \% 24$ animals were used during the dry season in a randomized design. The animals were weighed and monitored for body condition (BC) every 21 days. The inclusion of sunflower cake improved the average daily gain in $45.8 \%$. The efficiency of the use of concentrated supplements was higher for supplements containing sunflower cake with values of 12.26; 13.42 and $9.87 \mathrm{~kg} / \mathrm{kg}$ for the replacement levels of $20 ; 40$ and $60 \%$. The supplement without sunflower cake had efficiencies of $7.31 \mathrm{~kg} / \mathrm{kg}$. The BC of animals has improved with the supplementation, of $3.6 ; 4.0 ; 4.0$ and 3.7 points, for replacement levels of $00 ; 20 ; 40$ and $60 \%$. For carcass characteristics there was no significant differences between the levels of 
substitution studied to slaughter weight, hot carcass weight, cold carcass weight, cooling losses, carcass yield, carcass length, back, front, yield estimated grade, Brazilian commercial cuts, AOL $/ 100 \mathrm{~kg}$, fat thickness, liver. There was effect for replacement of sunflower cake just for the accumulation of perirenal pelvic fat, where the replacement level of $60 \%$ had the highest value (3.67 kilograms). Partial substitution of soybean meal by sunflower cake improved the performance of heifers finished on pastures without changing the characteristics of the carcass.

Keywords: by-product, daily gain, fat thickness, supplementation, yield estimated grade

\section{INTRODUÇÃO}

As pastagens representam a forma mais prática e econômica de alimentação de bovinos, e responde por $95 \%$ do ganho total de peso dos animais abatidos anualmente (ANUALPEC, 2010). Nos países tropicais e subtropicais, os ruminantes são submetidos a flutuações estacionais quanto à disponibilidade e qualidade dos pastos, principalmente, durante a época seca, quando o crescimento das forragens diminui, o que leva, consequentemente, à redução da qualidade dos mesmos.

A redução na taxa de crescimento, ou mesmo a perda de peso dos animais devido à escassez de forragem na estação seca têm sido considerados os principais fatores que afetam a produtividade (BRITO et al., 2008). Dessa forma, a utilização de práticas de suplementação alimentar é uma alternativa essencial para garantir o desenvolvimento contínuo dos animais mantidos em condições de pastagens.

A torta de girassol é uma fonte alternativa de proteína e energia, cujos teores de proteína bruta $(\mathrm{PB})$ variam de 240 a $333 \mathrm{~g} / \mathrm{kg}$, nutrientes digestíveis totais (NDT) em torno de $790 \mathrm{~g} / \mathrm{kg}$ e 165g/kg de lipídeos (GOES et al. 2010; 2008b; DOMINGUES et al. 2010; OLIVEIRA et al. 2007). O óleo de girassol apresenta elevada proporção de ácidos graxos poli-insaturados (MIR et al., 2003) e tem como principal ácido graxo encontrado o ácido linoleico (FERNANDES et al., 2008). A PB da torta de girassol caracteriza-se por ser extensamente degradável, sendo a proteína não degradável no rúmen menor que $10 \mathrm{~g} / 100 \mathrm{~g}$ (BERAN et al., 2007). Entretanto, Goes et al. (2008b; 2010) encontraram degradabilidade ruminal da PB para a torta de girassol, de 36,65 e $50 \mathrm{~g} / 100 \mathrm{~g}$, respectivamente. A variação entre esses valores pode ser devido ao processo de extração do óleo ou à falta de uniformidade da torta em função da variedade utilizada, o que mostra a necessidade de uma padronização do produto.

O uso de coproduto de girassol, em substituição às fontes proteicas pode ser vantajoso economicamente, uma vez que permite que o farelo de soja seja liberado para outros fins, como a exportação (OLIVEIRA et al., 2007). No entanto, pesquisas que avaliam os níveis e os efeitos da inclusão da torta de girassol na dieta de bovinos de corte são escassas, apesar de serem fundamentais para a manipulação de dietas mais eficientes.

Objetivou-se com este trabalho avaliar a inclusão da torta de girassol, em substituição parcial ao farelo de soja no desempenho e nas características de carcaça de novilhas Nelore terminadas a pasto durante a estação seca do ano.

\section{MATERIAL E MÉTODOS}

O experimento foi desenvolvido na fazenda Cerro Azul, localizada entre as coordenadas geográficas $21^{\circ} 51^{\prime} 24^{\prime \prime} \mathrm{S}$ 
54 53'14”O, no município de Itaporã/MS, durante a época seca, entre os meses de junho e outubro de 2009, totalizaram 120 dias experimentais, dos quais os primeiros 15 dias foram para adaptação dos animais à dieta. A área experimental era de aproximadamente 12 hectares, divididos em quatro piquetes de três hectares, providos de cocho e bebedouro. Os pastos foram diferidos na primeira quinzena de março, para garantir massa de forragem suficiente para todo $\mathrm{o}$ período experimental.

$\mathrm{O}$ ensaio experimental foi implantado em uma área com pastagem de Brachiaria humidicola, estabelecida entre os anos de 1997 e 1998, sem adubação ou outra prática de manejo, pastejada desde sua implantação. Durante este ensaio e conforme demonstra a Tabela 1, houve baixa ocorrência de precipitações pluviométricas, extremo frio com ocorrência de fenômenos de geada.

Tabela 1. Média dos dados metereológicos entre os meses de Junho e Outubro de 2009, na região da Grande Dourados-MS

\begin{tabular}{lccccc}
\hline Item & $\begin{array}{c}\text { Temp. máx. } \\
\left({ }^{\circ} \mathrm{C}\right)\end{array}$ & $\begin{array}{c}\text { Temp. mín. } \\
\left({ }^{\circ} \mathrm{C}\right)\end{array}$ & $\begin{array}{c}\text { Temp. média } \\
\left({ }^{\circ} \mathrm{C}\right)\end{array}$ & $\begin{array}{c}\text { Precipitação } \\
(\mathrm{mm})\end{array}$ & $\begin{array}{c}\text { UR } \\
(\%)\end{array}$ \\
\hline Junho & 23,2 & 11,8 & 17,2 & 57,9 & 74,2 \\
Julho & 22,9 & 13,2 & 17,5 & 152,1 & 79,1 \\
Agosto & 26,2 & 14,7 & 20,1 & 152,9 & 70,0 \\
Setembro & 27,5 & 15,9 & 21,1 & 25,9 & 71,7 \\
Outubro & 30,3 & 18,4 & 23,7 & 301,5 & 72,4 \\
\hline
\end{tabular}

Fonte: Universidade Federal da Grande Dourados, 2009.

Foram utilizadas 24 novilhas Nelore, desverminadas com antiparasitário à base de Ivermectina $(1 \%)$ ao início do experimento; com peso inicial médio de $311,40 \pm 23,35 \mathrm{~kg}$ e condição corporal 2,3 pontos, segundo classificação proposta por Lowman et al. (1973), em que $1=$ estado muito magro e $5=$ muito gordo; com aproximadamente 24 meses de idade. Os animais foram distribuídos ao acaso nos piquetes e suplementados com concentrado correspondente a $8 \mathrm{~g} / \mathrm{kg}$ de peso corporal até as $10 \mathrm{~h}$ em cocho coletivo que media $3,0 \times 0,5 \mathrm{~m}$. Os suplementos foram balanceados, conforme NRC (2000), para conter $280 \mathrm{~g} / \mathrm{kg}$ de $\mathrm{PB}$ e foram constituídos com torta de girassol em substituição parcial ao farelo de soja, nas proporções de $0 ; 20$; 40 e $60 \%$ (Tabela 2).

Os animais foram pesados e monitorados quanto ao grau de acabamento e escore de condição corporal, a cada 21 dias, O monitoramento era realizado por três avaliadores treinados, e definido para critério de abate o mínimo de três, que resultaria numa gordura de cobertura de $3 \mathrm{~mm}$, conforme descrito por Kuss et al. (2008). As pesagens eram realizadas em balança mecânica até as $08 \mathrm{~h}$, após jejum de sólidos e líquidos de 18 horas. Após a pesagem, os suplementos eram corrigidos de acordo com o peso vivo dos animais e, ao final de cada período experimental os animais eram rotacionados nos piquetes a fim de eliminar possíveis variações decorrentes da forragem. 
Rev. Bras. Saúde Prod. Anim., Salvador, v.13, n.2, p.396-409 abr./jun., 2012 http://www.rbspa.ufba.br ISSN 15199940

Tabela 2. Participação dos ingredientes ( $\mathrm{g} / \mathrm{kg}$ de matéria natural) e composição bromatológica dos concentrados ( $\mathrm{g} / \mathrm{kg}$ de Matéria Seca - MS)

\begin{tabular}{lcccc}
\hline Ingredientes & ${\mathrm{C} 00^{\#}}^{\#}$ & ${\mathrm{C} 20^{\#}}^{\#}$ & $\mathrm{C}^{\#} 0^{\#}$ & $\mathrm{C60}^{\#}$ \\
\hline Milho & 426 & 357 & 287 & 218 \\
Farelo de soja & 524 & 419 & 315 & 210 \\
Torta de girassol & -- & 174 & 348 & 522 \\
Mineral & 50 & 50 & 50 & 50 \\
\hline Parâmetros & \multicolumn{5}{c}{ Composição Bromatológica (g/kg de MS) } \\
\hline MS & 915,1 & 874,6 & 879,7 & 910,3 \\
PB & 283,5 & 278,7 & 279,1 & 274,6 \\
EE & 36,8 & 56,5 & 88,2 & 110,0 \\
FDN & 269,8 & 293,2 & 304,4 & 324,8 \\
FDA & 55,1 & 138,6 & 171,6 & 187,3 \\
NDT* & 851,2 & 820,0 & 783,8 & 760,0 \\
MM & 32,5 & 31,9 & 43,0 & 52,8 \\
\hline
\end{tabular}

\# C00 = Concentrado sem a inclusão de torta de girassol; C20 = Concentrado com substituição de $20 \%$ do farelo de soja pela torta de girasol; C40 = Concentrado com substituição de $40 \%$ do farelo de soja pela torta de girasol; $\mathrm{C} 60=$ concentrado com substituição de $60 \%$ do farelo de soja pela torta de girasol.

MS = materia seca; $\mathrm{PB}=$ proteína bruta; $\mathrm{EE}=$ extrato etéreo; $\mathrm{FDN}$ = fibra em detergente neutro; FDA = fibra em detergente ácido; NDT = nutrientes digestívies totais; $\mathrm{MM}=$ matéria mineral.

* \%NDT = 9,6134+0,829DMS. Capelle et al. (2001).

A eficiência do uso dos suplementos foi determinada através da relação entre kg de ganho de peso/kg de suplemento consumido.

No $1^{\circ}$ dia experimental, para a estimativa da disponibilidade total de matéria seca (kg/ha) utilizou-se o método do quadrado metálico, com área de $0,25 \mathrm{~m}^{2}$, no qual, procedeu-se o corte da forragem rente ao solo em 40 áreas por piquete. Além do corte, também foi realizada a determinação da altura média do pasto com o auxílio de uma régua. Posteriormente, as amostras foram uniformizadas por piquete onde se retiraram duas amostras, uma para a determinação da composição bromatológica e outra para a quantificação da composição botânica. Todas as amostras foram armazenadas em sacolas plásticas previamente identificadas e congeladas à $-10^{\circ} \mathrm{C}$, para posteriores análises laboratoriais.

Para a determinação da composição botânica (folha, colmo e material senescente), realizou-se a separação das porções de forma manual, a olho nu, onde, em seguida, fez-se a pesagem das proporções, bem como os valores percentuais.

A estimativa da pastagem ingerida foi feita pelo método do pastejo simulado, mediante a observação cuidadosa da preferência animal quanto às partes da planta ingerida, da área pastejada, da altura e das partes da planta que estavam sendo consumidas (GOES et al., 2003). As amostras foram colhidas pelo mesmo observador, manualmente, para evitar discrepâncias entre as coletas.

Todas as amostras foram encaminhadas para o Laboratório de Nutrição Animal da FCA/UFGD, onde foram realizadas análises de teores de matéria seca (MS), proteína bruta $(\mathrm{PB})$, extrato etéreo $(\mathrm{EE})$, fibra em detergente neutro (FDN), e ácido (FDA), lignina (LIG), conforme metodologias descritas por Silva \& Queiroz (2002). Para a determinação da 
FDN e FDA foi utilizado o equipamento da Tecnal $^{\circledR}$ (TE-149), com o uso de saquinhos $(5,0 \times 5,0 \mathrm{~cm})$ confeccionados com tecido não tecido (TNT) de gramatura de $100 \mathrm{~g} / \mathrm{m}^{2}$ (CASALI et al., 2008). Para a determinação de lignina (LIG) os resíduos obtidos com a análise de FDA foram transferidos para cadinhos filtrantes, para dar continuidade ao método sequencial, mediante a extração da lignina por permanganato.

Os teores de NDT da pastagem e do concentrado foram estimados segundo equações propostas por Capelle et al. (2001). O teor de NDT da forragem foi calculado baseado no teor de FDA, conforme equação: \%NDT $=74,49-$ $0,5635^{*}$ FDA $\left(r^{2}=0,82\right)$ e o teor de NDT do concentrado foi estimado baseado na digestibilidade in vitro da matéria seca (DMS), em que \%NDT = 9,6134+0,829DMS $\left(r^{2}=0,98\right)$.

Para a determinação do consumo de matéria seca da forragem utilizou-se o método de corte ou diferença agronômica, no qual, o consumo foi verificado pela diferença entre o total de forragem ofertada $\mathrm{e}$ a recusada. A redução observada na massa forrageira ofertada foi dividida pelo produto do número de animais e o tempo de pastejo (BURNS et al., 1994), segundo a equação: $\mathrm{CMSF}=(\mathrm{Mi}-\mathrm{Mf}) / \mathrm{NA}^{*} \mathrm{TP}$; onde CMSF = consumo de matéria seca da forragem, Mi e Mf = massa total disponível ao início e final do período de pastejo, respectivamente $(\mathrm{kg} / \mathrm{ha})$; NA = número de animais (animais/ha); e TP $=$ tempo de pastejo (dias).

Ao final do período experimental, quando as novilhas apresentaram condição corporal média de 3,8 e peso vivo de $378,5 \pm 7,75 \mathrm{~kg}$, foram submetidas a jejum de sólidos de 24 horas e, posteriormente, abatidas em frigorífico comercial localizado na cidade de Dourados/MS. Os animais foram divididos em dois lotes (primeiro lote tratamentos $\mathrm{C} 20$ e $\mathrm{C} 40$ e segundo lote C00 e C60) com diferença de uma semana entre os abates, devido a agendamento de escalas.

Antes do abate, os animais foram submetidos aos procedimentos de atordoamento por concussão cerebral, mediante utilização de pistola de dardo cativo penetrante e posterior sangria por secção da jugular, conforme descrito por Roça (2002). Na linha de abate, após a completa sangria, esfola e evisceração, foi tomada a pesagem do fígado, da gordura perirrenal-pélvica, determinado o comprimento de carcaça (medida entre o osso do púbis e a $1^{\circ}$ costilhar) e determinação do peso da carcaça quente (PCQ). Com o PCQ foi calculado o rendimento de carcaça quente por comparação percentual ao peso de abate. Em seguida, as carcaças foram identificadas e armazenadas em câmara fria a $2^{\circ} \mathrm{C}$ por 24 horas.

Após 24 horas de refrigeração foram determinados os pesos das carcaças frias $(\mathrm{PCF})$, rendimentos de dianteiro e de traseiro completo e calculado a percentagem de perda de peso da carcaça com o resfriamento. Na meia-carcaça esquerda, entre a $12^{\mathrm{a}}$ e a $13^{\mathrm{a}}$ costela foi feito um corte para expor a seção transversal do músculo Longissimus, para se determinar a área de olho de lombo (AOL) através de desenho por sobreposição de lâmina de transparência, pelo método do quadrante de pontos; e a espessura de gordura (ESPGord) nessa mesma peça, com o uso de um paquímetro digital, no terceiro quarto de seu comprimento à partir da coluna vertebral.

O rendimento de carne aproveitável total (CAT) e o rendimento de cortes comerciais brasileiros (CCB) foram determinados com aplicação de equações de predição propostas por Felício \& Allen (1982), onde: CAT= 72,92-0,489ESPGord -0,02 PCQ+ 0,119 
Rev. Bras. Saúde Prod. Anim., Salvador, v.13, n.2, p.396-409 abr./jun., 2012 http://www.rbspa.ufba.br ISSN 15199940

$\mathrm{AOL})$ e $\mathrm{CCB}==60,33-0,015$ PCQ-0, 462ESPGord+ 0,11 AOL).

Nas meias carcaças direitas foi determinado o rendimento de cortes comercias para o traseiro especial, conforme descrito por Gomide et al. (2006): Alcatra completa: (Miolo da alcatra, Picanha e Maminha); Coxão duro; Coxão mole; Lagarto; Patinho; Ponta de agulha (costela do traseiro).

$\mathrm{O}$ experimento foi realizado em delineamento inteiramente casualizado (DIC), composto de quatro tratamentos e seis repetições, segundo o modelo: $Y i j=$ $\mu+\mathrm{Ti}+\mathrm{e}(\mathrm{i}) \mathrm{j}$; Em que: $\mu=$ constante geral; $\mathrm{Ti}=$ efeito referente ao nível de inclusão $i$, sendo $i=1,2,3$ e 4 e e(i)j $=$ erro aleatório, associado a cada observação, pressuposto NID $\left(0 ; I^{2}\right)$. As análises de variância foram realizadas com o uso do pacote estatístico SAEG 9.1
(UFV, 2007) e as médias comparadas pelo teste de Tukey adotando-se $\alpha=0,05$.

\section{RESULTADOS E DISCUSSÃO}

Os animais foram expostos a uma disponibilidade total de matéria seca média de $4.566,25 \mathrm{~kg} / \mathrm{ha}$, disponibilidade de matéria verde (folhas + caule) de $2.965,5 \mathrm{~kg} / \mathrm{ha}$, altura média de $33 \mathrm{~cm} \mathrm{e}$ pressão de pastejo média de $230,67 \mathrm{~kg}$ de MS/100 kg de peso corporal (Tabela 3), por todo o período experimental. A disponibilidade de matéria seca apresentou valores superiores ao proposto por Silva et al. (2009), de $4.500 \mathrm{~kg} / \mathrm{ha}$ de MS e de $1.200 \mathrm{~kg} /$ ha de Matéria Verde, como limitante para o consumo animal, o que garantiu a seletividade da forrageira dos animais.

Tabela 3. Médias de disponibilidade de MS e MS Verde, altura, proporção de folha caule e material senescente, e teores de matéria seca (MS), proteína bruta (PB) e fibra em detergente neutro (FDN) e ácido (FDA), lignina, nutrientes digestíveis totais (NDT) e relação NDT/PB, da pastagem de $B$. humidicola

\begin{tabular}{lccccc}
\hline \multirow{2}{*}{ Item } & \multicolumn{4}{c}{ Substituição do farelo de soja (\%) } & \multirow{2}{*}{ Média } \\
\cline { 2 - 5 } & 00 & 20 & 40 & 60 & \\
\hline Disponibilidade de MS (kg/ha) & $4.699,0$ & $4.775,0$ & $4.144,0$ & $4.647,0$ & $4.566,25$ \\
Disponibilidade de MSVerde (kg/ha) & $2.941,6$ & $3.170,6$ & $2.701,8$ & $3.048,4$ & $2.965,60$ \\
Kg MS/100 kg de peso corporal & 236,39 & 237,28 & 210,48 & 238,52 & 230,67 \\
Altura (cm) & 34,6 & 33,6 & 30,5 & 33,7 & 33,10 \\
Folha (\%) & 29,8 & 34,8 & 36,9 & 35,9 & 34,35 \\
Caule (\%) & 32,8 & 31,6 & 28,3 & 29,7 & 30,60 \\
Material Senescente (\%) & 37,9 & 33,5 & 34,8 & 34,2 & 35,10 \\
\hline Matéria Seca (g/100g) & 50,2 & 53,8 & 52,1 & 49,8 & 51,48 \\
Proteína Bruta (g/100g) & 3,9 & 3,9 & 4,2 & 4,2 & 4,05 \\
FDN (g/100g) & 88,9 & 88,7 & 90,1 & 90 & 89,43 \\
FDA (g/100g) & 48,6 & 47,5 & 47,1 & 46,5 & 47,43 \\
Lignina (g/100g) & 11,5 & 11,5 & 10,3 & 10,5 & 10,95 \\
NDT (\%)* & 47,10 & 47,72 & 47,94 & 48,24 & 47,75 \\
NDT/PB & 12,07 & 12,24 & 11,41 & 11,49 & 11,80 \\
\hline *\%NDT = 74,49 - 0,5365FDA. Capelle et al., (2001). & & & &
\end{tabular}


As médias dos valores de $\mathrm{PB}$ mantiveram-se em torno de $40 \mathrm{~g} / \mathrm{kg}$, abaixo do limite mínimo de $70 \mathrm{~g} / \mathrm{kg}$, o que as tornam fator limitante para adequada atividade e crescimento microbiano, com prejuízos à digestibilidade da forragem com elevados teores de lignificação, o que pode ser identificado pelo elevado teor de FDN e FDA da forrageira
(Tabela 3). A relação NDT: PB média da pastagem foi de 11,80 , o que melhorou o desempenho animal, em decorrência do maior aporte proteico e da melhor relação energia:proteína, isso potencializou a degradação das forragens e melhorou a eficiência da microbiota ruminal (GOES et al. 2008a).

Tabela 4. Valores médios para peso vivo inicial (PVI) e final (PVF), ganho de peso diário (GDP), condição corporal inicial (CCI), condição corporal final (CCF), consumo de matéria seca do suplemento (CSUPL), forragem (CMSF) e total (CMST), e eficiência do uso de concentrados apresentada pelos animais

\begin{tabular}{|c|c|c|c|c|c|c|}
\hline \multirow{2}{*}{ Item } & \multicolumn{4}{|c|}{ Substituição de farelo de soja } & \multirow{2}{*}{ Média e DP } & \multirow{2}{*}{$\begin{array}{l}\mathrm{CV} \\
(\%)\end{array}$} \\
\hline & 00 & 20 & 40 & 60 & & \\
\hline PVI (kg) & $318,6^{\mathrm{a}}$ & $313,8^{\mathrm{a}}$ & $305,2^{\mathrm{a}}$ & $308^{\mathrm{a}}$ & $311,4 \pm 23,35$ & 7,9 \\
\hline $\operatorname{PVF}(\mathrm{kg})$ & $344^{\mathrm{a}}$ & $357^{\mathrm{a}}$ & $351,4^{\mathrm{a}}$ & $341,4^{\mathrm{a}}$ & $348,5 \pm 30,07$ & 9,2 \\
\hline GPD (kg/dia) & $0,242^{\mathrm{b}}$ & $0,411^{\mathrm{a}}$ & $0,440^{\mathrm{a}}$ & $0,320^{\mathrm{a}}$ & $0,350 \pm 0,14$ & 36,4 \\
\hline $\mathrm{CCI}$ & $2,1^{\mathrm{a}}$ & $2,2^{\mathrm{a}}$ & $2,5^{\mathrm{a}}$ & $2,2^{\mathrm{a}}$ & $2,3 \pm 0,34$ & 14,9 \\
\hline $\mathrm{CCF}$ & $3,6^{\mathrm{b}}$ & $4,0^{\mathrm{a}}$ & $4,4^{\mathrm{a}}$ & $3,7^{\mathrm{ab}}$ & $3,8 \pm 0,29$ & 6,5 \\
\hline CSUPL (kg/dia) & 2,65 & 2,68 & 2,63 & 2,60 & - & - \\
\hline CMSF (kg MS/dia) & $8,30^{\mathrm{a}}$ & $10,90^{\mathrm{a}}$ & $9,47^{\mathrm{a}}$ & $3,07^{\mathrm{a}}$ & $7,9 \pm 28,9$ & 44,6 \\
\hline CMST (kg MS/dia) & $10,9^{\mathrm{a}}$ & $13,6^{\mathrm{a}}$ & $12,1^{\mathrm{a}}$ & $5,7^{\mathrm{a}}$ & $10,5 \pm 28,9$ & 68,3 \\
\hline Eficiência & 7,31 & 12,26 & 13,42 & 9,97 & - & - \\
\hline
\end{tabular}

** Médias seguidas pelas mesmas letras não diferem entre si pelo teste de Tukey a 5\% de probabilidade.

A inclusão de torta de girassol elevou o ganho de peso diário (média de $0,350 \mathrm{~kg} / \mathrm{d}$ ) em $45,8 \%$ quando comparado à suplementação somente com milho e farelo de soja (Tabela 4). O ganho médio diário dos animais apresentou resposta quadrática $(\mathrm{GMD}=0,2416+0,012 \mathrm{x}-$ $\left.0,0002 x^{2}, r^{2}=0,99\right)$, com ponto de máxima para $30 \%$ de substituição (Figura 1).

Os níveis de substituição de 20 e $40 \%$ apresentaram os maiores ganhos de peso, sem alteração do consumo total de matéria seca, que apresentaram valores médios de 13,58 e 12,1kg/dia de MS (Tabela 4). A substituição de $60 \%$ do farelo de soja reduziu o consumo de forragem em 52\%. Essa redução, provavelmente, está relacionada ao elevado teor de EE presente neste concentrado $(110 \mathrm{~g} / \mathrm{kg})$, o que pode desencadear respostas nos mecanismos de controle de consumo dos animais, principalmente o energético. A maior concentração de óleo pode levar a uma adstringência devido à oxidação lipídica, o que altera a estrutura e afeta padrões como odor, sabor e textura (RAMALHO \& JORGE, 2006), uma vez que os ácidos graxos insaturados são as estruturas mais suscetíveis ao processo oxidativo. 


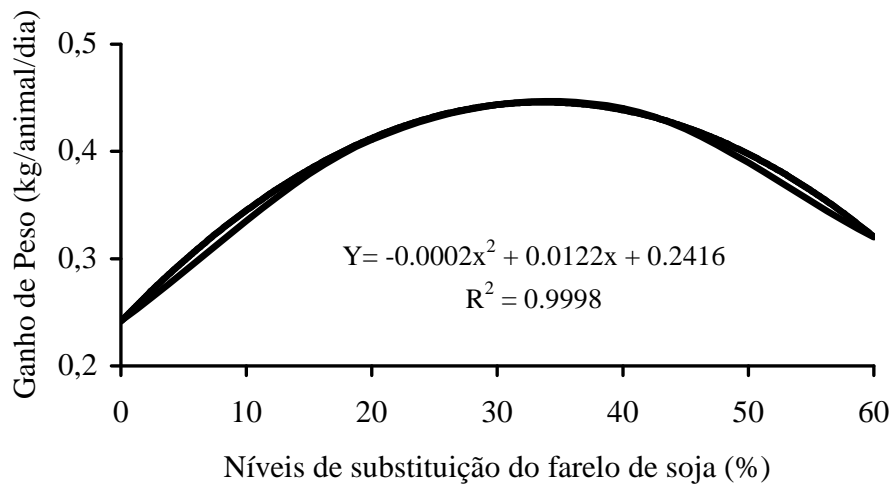

Figura 1. Ganho de peso diário de novilhas suplementadas com torta de girassol em substituição parcial ao farelo de soja

Alimentos ricos em lipídios levam à redução no CMS, na digestibilidade da MS e na relação acetato: propionato, pela qualidade do óleo contido no grão, que pode ser rico em ácidos graxos poliinsaturados os quais são biohidrogenados pelos micro-organismos ruminais, o que resulta em maior aporte energético para o animal. Segundo Van Soest (1994), os ácidos graxos insaturados possuem ação tóxica sobre os micro-organismos grampositivos presentes no rúmen, o que pode acarretar problemas relacionados ao decréscimo na degradação da fibra presente na dieta, com consequente diminuição na taxa de passagem e redução no CMS diário.

Os ganhos de peso médio diário dos animais foram influenciados pela qualidade da forrageira disponível, uma vez que o consumo de suplemento não foi alterado, com valor médio de $2,64 \mathrm{~kg} /$ dia. A eficiência do uso de concentrados ( $\mathrm{kg}$ de suplemento/kg de ganho de peso) foi positiva para todos os tratamentos avaliados e maiores para os suplementos que continham torta de girassol, 12,26; 13,42 e $9,87 \mathrm{~kg} / \mathrm{kg}$, para os níveis 20,40 e $60 \%$ de substituição ao farelo de soja, respectivamente. $\mathrm{O}$ suplemento sem torta de girassol foi o mais eficiente, com valor de $7,31 \mathrm{~kg} / \mathrm{kg}$, o que demonstra que esses valores estão relacionados à substituição de torta de girassol no concentrado, bem como com o ganho de peso dos animais. As eficiências apresentadas são típicas de suplementação energética, sem deficiência de nitrogênio (BODINE \& PURVIS, 2003), onde se tem indícios de substituição, ou ineficiência de utilização dos nutrientes presentes no suplemento. Ressalta-se que, apesar de ter ocorrido redução do consumo total de matéria seca dos animais para o nível de substituição de $60 \%$ não ocorreu efeito entre os tratamentos, possivelmente devido ao elevado coeficiente de variação (Tabela 4).

A condição corporal final (CC) dos animais melhorou com a substituição do farelo de soja pela torta de girassol, uma vez que os animais suplementados com torta de girassol com 20 e $40 \%$ de substituição ao farelo de soja apresentaram a melhor condição corporal final (4,0, e 4,0 pontos).

Não houve diferença significativa $(\mathrm{P}>0,05)$ entre os níveis de substituição estudados para as variáveis: peso de abate, peso de carcaça quente (PCQ), peso de carcaça fria $(\mathrm{PCF})$, perdas por resfriamento $(\mathrm{kg})$ e $(\%)$, rendimento de 
carcaça, comprimento de carcaça, rendimento de traseiro e dianteiro, carne aproveitável total (CAT), cortes comercial brasileiro (CCB), perdas por resfriamento, alcatra completa, coxão duro, coxão mole, ponta de agulha, área de olho de lombo/100 kg de carcaça (AOL/100kg), espessura de gordura (ESPGord), fígado e gordura perirrenal pélvica (Tabela 5).

Tabela 5. Valores médios para peso de abate, peso de carcaça quente, peso de carcaça fria, perdas por resfriamento, rendimento de carcaça, comprimento de carcaça, rendimento de traseiro completo, rendimento do dianteiro, carne aproveitável total (CAT), cortes comerciais brasileiros (CCB), área de olho de lombo (AOL) e AOL/100 kg carcaça, espessura de gordura (EG), peso do fígado e peso da gordura perirrenal-pélvica

\begin{tabular}{|c|c|c|c|c|c|c|}
\hline \multirow{2}{*}{ Item } & \multicolumn{4}{|c|}{ Substituição de farelo de soja } & \multirow{2}{*}{ Média } & \multirow{2}{*}{$\mathrm{CV}(\%)$} \\
\hline & $\mathrm{C} 00$ & $\mathrm{C} 20$ & $\mathrm{C} 40$ & C60 & & \\
\hline Peso de abate (kg) & $374,2^{\mathrm{a}}$ & $389,0^{\mathrm{a}}$ & $375,2^{\mathrm{a}}$ & $375,6^{\mathrm{a}}$ & $378,5 \pm 7,75$ & 9,19 \\
\hline Peso de carcaça quente $(\mathrm{kg})$ & $195,6^{\mathrm{a}}$ & $204,4^{\mathrm{a}}$ & $196,6^{\mathrm{a}}$ & $191,6^{\mathrm{a}}$ & $197,1 \pm 18,37$ & 9,82 \\
\hline Peso de carcaça fria $(\mathrm{kg})$ & $190,3^{\mathrm{a}}$ & $202,1^{\mathrm{a}}$ & $193,7^{\mathrm{a}}$ & $187,3^{\mathrm{a}}$ & $193,3 \pm 17,82$ & 9,52 \\
\hline Perda por resfriamento $(\mathrm{kg})$ & $5,3^{\mathrm{a}}$ & $2,4^{\mathrm{a}}$ & $2,8^{\mathrm{a}}$ & $4,3^{\mathrm{a}}$ & $3,7 \pm 2,27$ & 56,86 \\
\hline Perda por resfriamento $(\%)$ & $2,7^{\mathrm{a}}$ & $1,1^{\mathrm{a}}$ & $1,5^{\mathrm{a}}$ & $2,3^{\mathrm{a}}$ & $1,9 \pm 1,15$ & 54,13 \\
\hline Rendimento de carcaça (\%) & $52,3^{\mathrm{a}}$ & $52,5^{\mathrm{a}}$ & $52,4^{\mathrm{a}}$ & $51,0^{\mathrm{a}}$ & $52,4 \pm 1,21$ & 2,14 \\
\hline Comprimento de carcaça (m) & $1,2^{\mathrm{a}}$ & $1,2^{\mathrm{a}}$ & $1,2^{\mathrm{a}}$ & $1,2^{\mathrm{a}}$ & $1,2 \pm 0,04$ & 3,35 \\
\hline Traseiro completo $(\mathrm{kg})$ & $58,9^{\mathrm{a}}$ & $64,1^{\mathrm{a}}$ & $60,7^{\mathrm{a}}$ & $57,7^{\mathrm{a}}$ & $60,4 \pm 6,28$ & 10,45 \\
\hline Dianteiro $(\mathrm{kg})$ & $36,9^{\mathrm{a}}$ & $39,1^{\mathrm{a}}$ & $37,0^{\mathrm{a}}$ & $38,9^{\mathrm{a}}$ & $38,0 \pm 3,79$ & 10,47 \\
\hline $\operatorname{CAT}(\%)+$ & $74,9^{\mathrm{a}}$ & $73,2^{\mathrm{a}}$ & $73,5^{\mathrm{a}}$ & $75,1^{\mathrm{a}}$ & $74,2 \pm 1,37$ & 1,58 \\
\hline $\mathrm{CCB}(\%)++$ & $62,8^{\mathrm{a}}$ & $61,3^{\mathrm{a}}$ & $61,5^{\mathrm{a}}$ & $62,9^{\mathrm{a}}$ & $62,1 \pm 1,23$ & 1,68 \\
\hline $\operatorname{AOL}\left(\mathrm{cm}^{2}\right)$ & $69,2^{\mathrm{a}}$ & $58,2^{\mathrm{b}}$ & $57,8^{\mathrm{b}}$ & $64,0^{\mathrm{ab}}$ & $62,3 \pm 7,10$ & 9,15 \\
\hline AOL/100 kg carcaça & $36,6^{\mathrm{a}}$ & $28,9^{\mathrm{a}}$ & $30,0^{\mathrm{a}}$ & $34,6^{\mathrm{a}}$ & $32,5 \pm 5,19$ & 13,50 \\
\hline Espessura de gordura (mm) & $4,7^{\mathrm{a}}$ & $5,2^{\mathrm{a}}$ & $4,8^{\mathrm{a}}$ & $3,4^{\mathrm{a}}$ & $4,5 \pm 1,51$ & 32,19 \\
\hline Fígado $(\mathrm{kg})$ & $3,7^{\mathrm{a}}$ & $3,7^{\mathrm{a}}$ & $3,4^{\mathrm{a}}$ & $3,7^{\mathrm{a}}$ & $3,6 \pm 0,4$ & 11,35 \\
\hline Gord.perirrenal-pélvica $(\mathrm{kg})^{*}$ & $1,8^{\mathrm{c}}$ & $2,3^{\mathrm{b}}$ & $2,1^{\mathrm{b}}$ & $3,7^{\mathrm{a}}$ & $2,4 \pm 0,82$ & 30,13 \\
\hline
\end{tabular}

O peso do fígado apresentou média de $3,59 \mathrm{~kg}$. Owens et al. (1993) e Kuss et al. (2008), destacaram que, a massa visceral de órgãos é proporcional ao consumo de nutrientes, aumentando o seu tamanho de acordo com o aumento das exigências energéticas dos animais, o que não ocorreu neste trabalho.
O comprimento da carcaça apresenta correlação positiva com o peso de abate, traseiro e dianteiro (OLIVEIRA et al., 2010), correlação esta que não foi observada no presente trabalho, no qual, para o comprimento carcaça e para rendimento de carcaça não foram observadas diferenças significativas. 
Verificou-se efeito $(\mathrm{P}<0,05)$ para substituição da torta de girassol somente para área de olho de lombo (AOL), porém, quando a mesma é convertida em porcentagem $(\mathrm{AOL} / 100 \mathrm{~kg})$ não se observa diferença significativa, o que demonstra que os animais produziram carcaças com porções comestíveis semelhantes e proporcionaram similares rendimentos de cortes de alto valor comercial (LUCHIARI FILHO, 2000), o que pode ser visto na Tabela 6 .

Os animais apresentaram valor médio de AOL de $32,54 \mathrm{~cm}^{2} / 100 \mathrm{~kg}$ de carcaça, superior a recomendação mínima de $29 \mathrm{~cm}^{2} / 100 \mathrm{~kg}$ de carcaça, proposta por Luchiari Filho (2000). Os valores apresentados para AOL/100kg, indicam capacidade de desenvolvimento muscular dos animais. Com o aumento da AOL, aumenta a porção comestível da carcaça; portanto, esse corte é um indicador de desenvolvimento muscular (LUCHIARI FILHO, 2000).

A espessura de gordura, segundo Luchiari Filho (2000) deve situar-se entre 5 e $7 \mathrm{~mm}$, sendo que, do ponto de vista qualitativo é necessário mínimo de $3 \mathrm{~mm}$ para se considerar um animal acabado e pronto para o abate (KUSS et al., 2008). O valor médio observado foi de $4,52 \mathrm{~mm}$, dentro do limite proposto, o que indica que as carcaças atingiram acabamento, sem excesso de gordura. $\mathrm{O}$ excesso de gordura poderia resultar em desperdício e/ou menor rendimento da porção comestível (KUSS et al., 2008). Para que a cobertura de gordura seja considerada homogênea em sua distribuição e seja efetiva na proteção da carcaça contra os efeitos negativos do resfriamento são necessários de 6 a 10mm (GOMIDE et al., 2006). Não houve efeito da perda de resfriamento das carcaças (Tabela 5). A adição de torta de girassol na dieta de novilhas aumentou a deposição de gordura perirrenal pélvica, em $96 \%$ para o nível de substituição de $60 \%$, relacionado, possivelmente, com o maior teor de EE presente no concentrado fornecido.

A ausência de diferenças significativas nas médias de CAT estimadas pode ser explicada pela semelhança observada nas características das carcaças, especialmente na ESPGord e AOL, considerados bons indicadores da proporção de carne na carcaça.

A estimativa do rendimento dos cortes da carcaça é de suma importância para complementar a avaliação do desempenho do animal durante $o$ seu desenvolvimento. É desejável que carcaças permitam o máximo aproveitamento de cortes cárneos, para agregar a estes produtos maior valor comercial. Os rendimentos para os seguintes cortes comerciais: alcatra, coxão duro, coxão mole e ponta de agulha em relação ao peso da carcaça, não foram significativos, com valores médios apresentados de 3,18; 2,09; 3,98 e $5,06 \mathrm{~kg} / \mathrm{kg}$. Vaz et al. (2002) referiram que a maior porcentagem de costilhar na carcaça está correlacionada ao acúmulo de gordura neste corte, característico dos animais que atingem elevado grau de acabamento. Apesar dos animais apresentarem acabamento, o rendimento de ponta de agulha não apresentou efeito significativo $(\mathrm{P}>0,10)$.

Apenas ocorreu significância para o corte lagarto, que apresentou valor médio de $1,88 \mathrm{~kg}$ e $0,97 \mathrm{~kg} / \mathrm{kg}$. Costa et al. (2010), ao trabalharem com fêmeas Nelore de descarte, de oito anos e peso de $360,28 \mathrm{~kg}$, encontraram rendimento de $2,59 \mathrm{~kg} / \mathrm{kg}$ para o lagarto, superior ao obtido neste trabalho.

Felício (1988) descreveu a proporção dos cortes comerciais de animais zebuínos em relação à carcaça fria com peso médio de $250 \mathrm{~kg}$, sendo: alcatra completa $4,7 \mathrm{~kg} / \mathrm{kg}$; coxão duro $4,4 \mathrm{~kg} / \mathrm{kg}$; coxão mole $6,6 \mathrm{~kg} / \mathrm{kg}$; lagarto $1,8 \mathrm{~kg} / \mathrm{kg}$; patinho $4 \mathrm{~kg} / \mathrm{kg}$; ponta de agulha $14 \mathrm{~kg} / \mathrm{kg}$. Neste 
Rev. Bras. Saúde Prod. Anim., Salvador, v.13, n.2, p.396-409 abr./jun., 2012 http://www.rbspa.ufba.br ISSN 15199940

ensaio a proporção dos cortes comerciais em relação à carcaça fria (Tabela 6), foi para uma carcaça de $193,3 \mathrm{~kg}$. Se esses valores fossem convertidos para uma carcaça de $250 \mathrm{~kg}$, seriam de 4,11;2,70; 5,$14 ; 1,25 ; 3,0$ e $6,54 \mathrm{~kg} / \mathrm{kg}$, para alcatra completa; coxão duro; coxão mole; lagarto; patinho e ponta de agulha, respectivamente; o que estariam de acordo com os resultados obtidos por Felício (1988).

Tabela 6. Valores médios para rendimentos de cortes comerciais do traseiro especial (kg e g/kg peso corporal) dos animais suplementados com torta de girassol em substituição parcial ao farelo de soja

\begin{tabular}{|c|c|c|c|c|c|c|}
\hline \multirow{2}{*}{ Item (\% da carcaça) } & \multicolumn{4}{|c|}{ Substituição de farelo de soja } & \multirow{2}{*}{ Média } & \multirow{2}{*}{$\mathrm{CV}(\%)$} \\
\hline & 00 & 20 & 40 & 60 & & \\
\hline Alcatra completa $(\mathrm{g} / \mathrm{kg})$ & $3,01^{\mathrm{a}}$ & $3,29^{\mathrm{a}}$ & $3,20^{\mathrm{a}}$ & $3,21^{\mathrm{a}}$ & $3,18 \pm 0,19$ & 5,52 \\
\hline Alcatra completa $(\mathrm{kg})$ & $5,71^{\mathrm{a}}$ & $6,66^{\mathrm{a}}$ & $6,20^{\mathrm{a}}$ & $6,01^{\mathrm{a}}$ & $6,15 \pm 0,79$ & 12,51 \\
\hline Coxão duro $(\mathrm{g} / \mathrm{kg})$ & $2,12^{\mathrm{a}}$ & $2,06^{\mathrm{a}}$ & $2,07^{\mathrm{a}}$ & $2,09^{\mathrm{a}}$ & $2,09 \pm 0,12$ & 6,09 \\
\hline Coxão duro (kg) & $4,01^{\mathrm{a}}$ & $4,16^{\mathrm{a}}$ & $4,00^{\mathrm{a}}$ & $3,89^{\mathrm{a}}$ & $4,02 \pm 0,43$ & 11,47 \\
\hline Coxão mole (g/kg) & $4,05^{\mathrm{a}}$ & $3,90^{\mathrm{a}}$ & $4,02^{\mathrm{a}}$ & $3,96^{\mathrm{a}}$ & $3,98 \pm 0,16$ & 4,09 \\
\hline Coxão mole (kg) & $7,66^{\mathrm{a}}$ & $7,86^{\mathrm{a}}$ & $7,77^{\mathrm{a}}$ & $7,34^{\mathrm{a}}$ & $7,66 \pm 0,63$ & 8,55 \\
\hline Lagarto $(\mathrm{g} / \mathrm{kg})$ & $1,02^{\mathrm{a}}$ & $0,96^{\mathrm{ab}}$ & $0,90^{\mathrm{b}}$ & $1,01^{\mathrm{a}}$ & $0,97 \pm 0.07$ & 6,65 \\
\hline Lagarto $(\mathrm{kg})$ & $1,93^{\mathrm{a}}$ & $1,95^{\mathrm{a}}$ & $1,75^{\mathrm{a}}$ & $1,88^{\mathrm{a}}$ & $1,88 \pm 0,24$ & 13,14 \\
\hline Patinho $(\mathrm{g} / \mathrm{kg})$ & $2,41^{\mathrm{a}}$ & $2,36^{\mathrm{a}}$ & $2,29^{\mathrm{a}}$ & $2,23^{\mathrm{a}}$ & $2,32 \pm 0,12$ & 4,55 \\
\hline Patinho (kg) & $4,56^{\mathrm{a}}$ & $4,76^{\mathrm{a}}$ & $4,44^{\mathrm{a}}$ & $4,15^{\mathrm{a}}$ & $4,48 \pm 0,47$ & 10,11 \\
\hline Ponta de agulha $(\mathrm{g} / \mathrm{kg})$ & $4,99^{\mathrm{a}}$ & $5,15^{\mathrm{a}}$ & $5,10^{\mathrm{a}}$ & $5,01^{\mathrm{a}}$ & $5,06 \pm 0,33$ & 7,12 \\
\hline Ponta de agulha $(\mathrm{kg})$ & $9,38^{\mathrm{a}}$ & $10,44^{\mathrm{a}}$ & $9,89^{\mathrm{a}}$ & $9,31^{\mathrm{a}}$ & $9,75 \pm 1,07$ & 10,81 \\
\hline
\end{tabular}

Os valores obtidos podem ser justificados pelo toilette que foi realizado, no qual a limpeza do corte foi realizada de forma bem rigorosa.

A utilização da torta de girassol pode ser utilizada em suplementos para animais mantidos a pasto, em substituição parcial ao farelo de soja em ate $40 \%$. Deve-se, para tanto, considerar a disponibilidade e o custo do produto na região.

\section{AGRADECIMENTOS}

Ao $C N P q$ e a UFGD, pelas bolsas concedidas e ao CNPq; Fundect/MS pelo apoio financeiro a este trabalho. À Maria Gizelma de Menezes Gressler pelo auxílio nas conduções das análises laboratoriais. À Fazenda Cerro Azul, á casa de carnes Beef Beef e ao Abatedouro São Luiz, que tornaram possível este trabalho. 
Rev. Bras. Saúde Prod. Anim., Salvador, v.13, n.2, p.396-409 abr./jun., 2012 http://www.rbspa.ufba.br ISSN 15199940

\section{REFERÊNCIAS}

ANUALPEC. Anuário da Pecuária

Brasileira. São Paulo: Instituto FNP, 2010. 420p.

BERAN, F.H.B.; SILVA, L.D.F.; RIBEIRO, E.L.A.; ROCHA, M.A.; EZEQUIEL, J.M.B.; CORREA, R.A.; CASTRO, V.S.; SILVA, K.C.F. Avaliação da digestibilidade de nutrientes, em bovinos, de alguns alimentos concentrados pela técnica dos três estágios. Revista Brasileira de Zootecnia, v.36, n.1, p.130-137, 2007.

BODINE, T.N.; PURVIS, H.T. Effects of supplemental energy and/or degradable intake protein on performance, grazing behavior, intake, digestibility, and fecal and blood indices by beef steers grazed on dormant native tallgrass prairie.

Journal of Animal Science, v.81, p.304317. 2003.

BRITO, R.M.; SAMPAIO, A.A.M.; FERNANDES,A.R.M.; RESENDE, K.T.; HENRIQUE, W.; TULLIO, R.R. Desempenho de bezerros em pastagem de capim-marandu recebendo suplementação com concentrados balanceados para diferentes níveis de produção. Revista Brasileira de Zootecnia, v.37, n.9, p.1641-1649, 2008.

BURNS, J.C.; POND, K.R.; FISHER, D.S. Measurement of forage intake. In: FAHEY JÚNIOR, G.C. (Ed.). Forage quality, evaluation, and utilization. Winsconsin: American Society of Agronomy, 1994. p.494-532.

CAPELLE, E.R.; VALADARES FILHO, S.C.; SILVA, J.F.C.; CECON, P.R.

Estimativas de valor energético a partir de características químicas e bromatológicas dos alimentos. Revista Brasileira de

Zootecnia, v.30, n.06, 1837-1856, 2001.
CASALI, A.O.; DETMANN, E.; VALADARES FILHO, S.C.; PEREIRA, J.C.; HENRIQUES, L.T.; FREITAS, S.G.; PAULINO, M.F. Influência do tempo de incubação e do tamanho de partículas sobre os teores de compostos indigestíveis em alimentos e fezes bovinas obtidos por procedimentos in situ. Revista Brasileira de Zootecnia, v.37, n.2, p.335-342, 2008.

COSTA, D.P.B; MOURÃO, R.C.; MOUSTACAS, V.S.; ABREU, J.B.R.; SOUSA, J.C.D.; VIEIRA, A.O.

Rendimento dos cortes comerciais da carcaça de vacas de descarte e de novilhos inteiros nelore, terminados em Brachiaria decumbens.

Agropecuária Científica no SemiÁrido, v.6, n.1, p.14-18, 2010.

DOMINGUES, A.R.; SILVA, L.D.F.; RIBEIRO, E.L.A.; CASTRO, V.S.; BARBOSA, M.A.A.F.; MORI, R.M.; VIEIRA, M.T.L.; SILVA, J.A.O. Consumo, parâmetros ruminais e concentração de uréia plasmática em novilhos alimentados com diferentes níveis de torta de girassol em substituição ao farelo de algodão. Semina: Ciências Agrárias, v.31, n.4, p.1059-1070, 2010.

FELÍCIO, P.E.; ALLEN, D.M. Previsão de rendimentos em carne aproveitável da carcaça de novilhos Zebu. Coleção Ital, n.12, p.203-217, 1982.

FELÍCIO, P.E.; O pecuarista recebe pela carne, mas o boi não é feito só de bifes. Conselho Regional de Medicina Veterinária, v.3, p.15-17, 1988. 
Rev. Bras. Saúde Prod. Anim., Salvador, v.13, n.2, p.396-409 abr./jun., 2012 http://www.rbspa.ufba.br ISSN 15199940

FERNANDES, A.R.M.; SAMPAIO, A.M.M.; HENRIQUE, W.; OLIVEIRA E.A.; TULLIO, R.R.; PERECIN D. Características da carcaça e da carne de bovinos sob diferentes dietas, em confinamento. Arquivos Brasileiros de Medicina Veterinária e Zootecnia, v.60, n.1, p.139-147, 2008.

GOES, R.H.T.B.; MANCIO, A.B.; LANA, R.P. VALADARES FILHO, S.C.; CECON, P.R.; QUEIROZ, A.C.; COSTA, R.M. Avaliação qualitativa da pastagem de capim tanner grass (Brachiaria arrecta), por três diferentes métodos de amostragem. Revista Brasileira de Zootecnia, v.32, n.1, p.64-69. 2003.

GOES, R.H.T.B.; LAMBERTUCCI, D.M.; BRABES, K.C.S.; ALVES, D.D. Suplementação protéica e energética para bovinos de corte em pastagens tropicais. Arquivo de Ciências Veterinárias e Zoologia da Unipar, v.11.n.2, p.129-137, 2008a.

GOES, R.H.T.B.; TRAMONTINI. R.C.M.; ALMEIDA. G.D.; CARDIM, S.T.; RIBEIRO, J.; OLIVEIRA. L.A.; MOROTTI. F.; BRABES. K.C.S.; OLIVEIRA. E.R. Degradabilidade ruminal da matéria seca e proteína bruta de diferentes subprodutos agroindustriais utilizados na alimentação de bovinos. Revista Brasileira de Saúde e Produção Animal [Online], v.9, n.4, p.715-725, 2008b.

GOES, R.H.T.B.; SOUZA, K.A.; PATUSSI, R.A.; CORNELIO, T.C.; OLIVEIRA, E.R.; BRABES, K. C. S. Degradabilidade in situ dos grãos de crambe, girassol e soja, e de seus coprodutos em ovinos. Acta Scientiarum. Animal Sciences, v.32, p.271-277, 2010.
GOMIDE, L.A.M.; RAMOS, E.M.; FONTES, P.R. Tecnologia de abate e tipificação de carcaças. Viçosa, MG: Universidade Federal de Viçosa, 2006. $370 \mathrm{p}$.

KUSS, F.; BARCELLOS, J.O.J.; LOPEZ, J.; RESTLE J.; MOLETTA J.L.; PAULA M.C. Componentes não integrantes de carcaça de novilhos não castrados ou castrados terminados em confinamento e abatidos aos 16 ou 26 meses de idade. Revista Brasileira de Zootecnia, v.37, n.10, p.1829-1836, 2008.

LOWMAN, B.G.; SCOTT, N.; SOMERVILLE, S. Condition scoring beef cattle. Edinburgh: East of Scotland College of Agriculture, 1973. 8p.

\section{LUCHIARI FILHO, A. Pecuária da carne bovina. São Paulo, 2000. 134p.}

MIR, P.S.; IVAN, M.; HE, M.L.; PINK, B.; OKINE, E.; GOONEWARDENE, L.; MCALLISTER, T.A.; WESELAKE,R.; MIR, Z; Dietary manipulation to increase conjugated linoleic acids and other desirable fatty acids in beef: a review. Canadian Journal of Animal Science, v.83, n.4, p.673-685, 2003.

NATIONAL RESEARCH COUNCIL NRC. Nutrient Requirements of Beef Cattle. 7th ed.Washington, DC:

National Academies Press, 2000. 233p.

OLIVEIRA, E.A.; SAMPAIO, A.A.M.; FERNANDES, A.R.M.; HENRIQUE, W.; ANDRADE, A.T.; ROSA, B.L.; PIVARO, T.M. Métodos de mensuração da área de olho de lombo e suas relações entre componentes da carcaça de touros jovens confinados. Revista Agrarian, v.3, n.9, p.216-223, 2010. 
Rev. Bras. Saúde Prod. Anim., Salvador, v.13, n.2, p.396-409 abr./jun., 2012 http://www.rbspa.ufba.br ISSN 15199940

OLIVEIRA, M.D.S.; MOTA, D.A.; BARBOSA, J.C., STEIN, M.;

BORGONOVI, F. Composição Bromatológica e Digestibilidade ruminal in vitro de concentrados contendo diferentes níveis de torta de girassol. Ciência Animal Brasileira, v.8, n.4, p. 629-638, 2007.

OWENS, F.N.; DUBESKI, P.; HANSON, C.F. Factors that alter the growth and the development of ruminants. Journal of Animal Science, v.71, p.3138-3150, 1993.

RAMALHO, V.C.; JORGE, N. Antioxidantes utilizados em óleos, gorduras e alimentos gordurosos. Química Nova, v.29, n.4, p.755-760, 2006

ROÇA, R.O. Abate humanitário de bovinos. In: CONFERÊNCIA VIRTUAL GLOBAL SOBRE PRODUÇÃO ORGÂNICA DE BOVINOS DE CORTE, 1., 2002, Corumbá. Anais.. Corumbá: EMBRAPA, 2002. p.1-15.

SILVA, D.J.; QUEIROZ, A.C. Análise de Alimentos: métodos químicos e biológicos. Viçosa: Universidade Federal de Viçosa, 2002. 239p.
SILVA, F.F.; SÁ, J.F.; SCHIO, A.R.; ITAVO. L.C.V.; SILVA, R.R.;

MATEUS, R.G. Suplementação a pasto: disponibilidade e qualidade $\mathrm{x}$ níveis de suplementação x desempenho. Revista Brasileira de Zootecnia, v.38, p.371389, 2009. Supl.

UNIVERSIDADE FEDERAL DE VIÇOSA - UFV - SAEG (Sistema de Análises Estatísticas e Genéticas). Versão 9.1. Viçosa, 2007. 142p.

VAN SOEST, P.J. Nutritional Ecology of the Ruminant. 2.ed. Ithaca, New York: Cornel University Press, 1994. 476p.

VAZ, F.N.; RESTLE, J.; VAZ, R. Z.; BRONDANI, I.L.; BERNARDES, R. A.L.C.; FATURI, C. Efeitos de raça e heterose na composição física da carcaça e na qualidade da carne de novilhos da primeira geração de cruzamento entre Charolês e Nelore.

Revista Brasileira de Zootecnia, v.31, n.1, p.376-386, 2002. Supl.

Data de recebimento: 15/07/2011

Data de aprovação: 24/04/2012 